\title{
Integrating El Niño-Southern Oscillation information and spatial diversification to minimize risk and maximize profit for Australian grazing enterprises
}

\author{
Thong Nguyen-Huy ${ }^{1,2}{ }^{(D)} \cdot$ Jarrod Kath $^{1} \cdot$ Shahbaz Mushtaq $^{1} \cdot$ David Cobon $^{1} \cdot$ Gordon Stone $^{1} \cdot$ Roger Stone $^{1}$
}

Accepted: 10 January 2020 / Published online: 29 January 2020

(C) INRAE and Springer-Verlag France SAS, part of Springer Nature 2020

\begin{abstract}
Climate strongly influences agricultural profitability. Climate risks on agriculture can be managed by moving production to other areas, but this may be costly and reduce profitability if climatic conditions are dynamic. Here, we test whether integrating spatial diversification and climate information could minimize climate risk, while not sacrificing profitability. We use 27 years of farm business profit and climate data (1991-2018) from four of Australia's most climatically diverse regions where grazing underpins socioeconomic activity. We show that spatial diversification coupled with seasonal climate information from El Niño-Southern Oscillation (ENSO) provides better estimates of optimized risk-profit tradeoffs in different ENSO years compared to estimates without climate information. Conditional Value-at-Risk (CVaR) (a measure of financial risk) is lower when climate information is used in El Niño (1.23 \$/ha), La Niña (1.19 \$/ha), and Neutral years (1.22 \$/ha), compared to when no climate information (1.57 $\$$ /ha) is used. When targeting high profits, CVaR is reduced by 15,86 , and $22 \%$ in El Niño, La Niña, and Neutral years, respectively, compared to a $5 \%$ reduction when no climate information is used. When aiming to minimize CVaR in drought (El Niño), profit is higher using climate-informed spatial diversification (expected profits of $2.71 \$ / \mathrm{ha}$ ), relative to when it is not (expected profits of $2.30 \$ / \mathrm{ha}$ ). Climate-informed spatial diversification also provides options to graziers to achieve much higher gains (expected profits of up to $\sim 4.13 \$ /$ ha) under La Niña versus $2.62 \$ /$ ha when no climate information is used. Here, we show for the first time that seasonal climate information coupled with spatial diversification can provide strategies to help graziers reduce risk and increase profitability. Our approach is applicable to other parts of the world and could be used to decrease climate risk and increase profitability for other agricultural sectors exposed to variable climatic conditions.
\end{abstract}

Keywords Copula $\cdot$ Portfolio optimization · Conditional value-at-risk · Agricultural risk management · Geographical diversification $\cdot$ Australia $\cdot$ Grazing $\cdot$ ENSO

\section{Introduction}

Climate variability and extreme events (e.g., droughts and heat waves) drive losses in livestock production systems worldwide (Godde et al. 2019). Drought events (1983/1984 and 1991/1992) have been identified as the single most important factor causing population changes in cattle herds in

Thong Nguyen-Huy

thonghuy.nguyen@usq.edu.au

1 Centre for Applied Climate Sciences, University of Southern Queensland, Toowoomba, QLD 4350, Australia

2 Vietnam National Space Center, Vietnam Academy of Science and Technology, Hanoi, Vietnam northern Kenya (Oba 2001). Consecutive droughts from 1999 to 2004, accounted for $30 \%$ of production losses suffered by farms and ranches in Utah, USA, corresponding to cumulative losses of around $\$ 133$ million (Coppock 2011). In Texas (USA), the 2011 drought resulted in losses of over $\$ 2.6$ billion in livestock production (Allred et al. 2014). Likewise in Australia, gross farm production has dropped by $27 \%$ on average during drought events over the past 50 years (Eslake 2018). More recently, the 2009-10 drought reduced the gross value of beef and veal production by $8.7 \%$ in southern Australia (Keogh et al. 2015). Figure 1 shows an example of drought impacts on grazing cattle across northeastern Australia (adapted from Marty et al. (2015)). Developing strategies to manage the influence of climate variability and drought on livestock production is therefore a major challenge. 


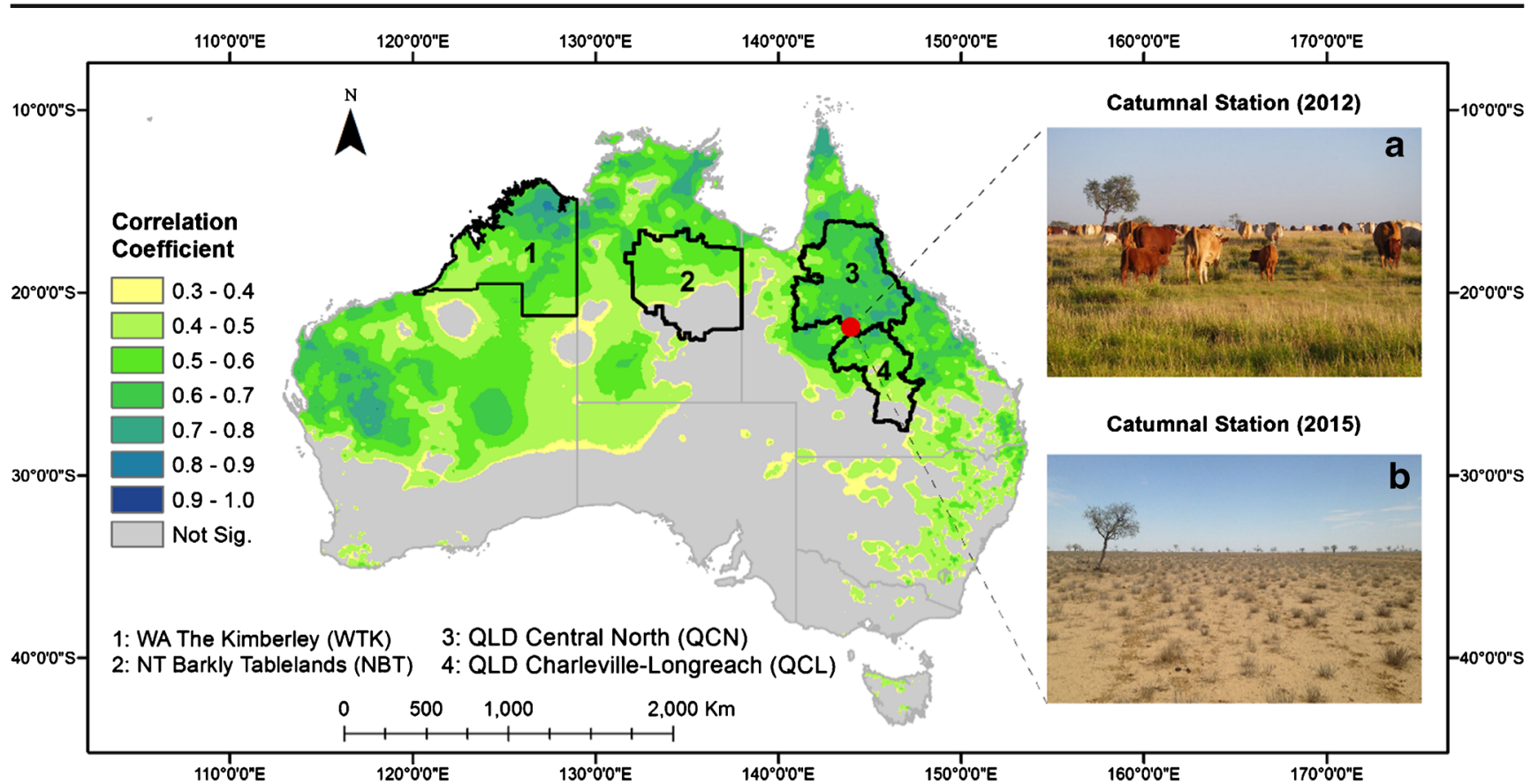

$\begin{array}{lll}110^{\circ} 0^{\circ} 0^{\circ} \mathrm{E} & 120^{\circ} 0^{\circ} 0^{\prime \prime} \mathrm{E} & 130^{\circ} 0^{\prime} 0^{\prime \prime} \mathrm{E} \\ \text { four study sites. These locations are important livestock }\end{array}$

Fig. 1 Map of four study sites. These locations are important livestock regions with different climate condition coefficients $(p$ value $<0.05$ ) between 6 -month average SOI and SPI. Six-month average SOI used to classified ENSO years is computed between June and March, starting in June and ending in any month between November and March, e.g., June-November, July-
December, and so on. Six-month average SPI is computed for the period of October-March. Drought impacts on a pasture at Catumnal Station in northeastern Australia. (a) Mustering healthy cattle in 2012 (during La Niña). (b) The same paddock can only support about 20 cows in 2015 (during El Niño) (adapted from Marty et al. (2015))
There are several strategies that can be used to manage the impact of climate risks on agriculture; the use of different crops or crop varieties, planting trees, soil conservation, changing planting dates, and irrigation (Bryan et al. 2009). In addition to these, spatial diversification, which is the spatial allocation of production to spread risk, is another strategy that is receiving increasing attention as a means of managing unfavorable climatic conditions on agriculture (Larsen et al. 2015; Nguyen-Huy et al. 2018; Akponikpe et al. 2011). Spatial diversification can be an effective strategy for managing farm production risk associated with climate variability and other factors (e.g., price fluctuations) in commodity markets (Bradshaw et al. 2004).

Larsen et al. (2015) evaluated the effectiveness of spatial diversification and showed that wheat producers in Texas can increase average profit margins by $3.7 \%$ in the worst $5 \%$ seasons (i.e., reduce their downside risk) by allocating $15 \%$ of production to Kansas. The reallocation of land to Kansas only minimally impacted $(-0.72 \%)$ expected profits. In Australia, spatial diversification has also been shown to reduce risks for wheat producers by $3.2 \%$ in the worst $5 \%$ of cases with a reduction of just $0.3 \%$ in expected profit margins (NguyenHuy et al. 2018). These findings indicate that spatial diversification is a viable risk management strategy for farmers. At smaller scales, Akponikpe et al. (2011) analyzed a spatial fields' spreading strategy to reduce agro-climatic risk at the household level in pearl millet-based farming systems in the
Sahel. The results indicated that increasing dispersion of millet fields could reduce yield variation.

Although the benefits of spatial diversification have been shown for a range of crops, its effectiveness has not been assessed for grazing systems. There are also no studies, in either grazing or cropping systems, that have coupled spatial diversification and seasonal climate information, despite the fact that (i) the livestock industries profitability is highly exposed to climate risk and especially drought and (ii) in many parts of the world, year-to-year variability in rainfall is high, with shifts in ENSO often being the main cause (Stone et al. 1996). ENSO is defined as a warming/cooling of Pacific equatorial Sea Surface Temperatures (El Niño/La Niña) associated with a dipole of mean sea level atmospheric pressure anomalies between Darwin and Tahiti (the Southern Oscillation) and with a marked periodicity of 2-7 years (Trenberth 1997).

Coupling spatial diversification with climate information, such as ENSO, is expected to help graziers to manage climate risks by providing information about when and where they should shift production in order to spread their risk under different climatic conditions. In particular, this could inform graziers when to shift livestock production systems to other areas, with anticipated more favorable climatic conditions, so they could minimize exposure to drought. This study evaluates the potential benefit of spatial diversification coupled with seasonal climate information for livestock business profitability in Australia. Australia exhibits a high degree of 
spatiotemporal climate variability, with ENSO the main factor influencing rainfall variability in many areas (Chowdhury and Beecham 2010). Australia was also the third-largest beef and veal exporter in 2017, accounting for approximate $2 \%$ of the world cattle herd, and 3\% of world beef production in 2016 (MLA 2018). The cattle herd was 26.2 million head (2017 June) operated by 48,000 businesses and 192,000 laborers. The gross value of cattle production was $\$ 11.4$ billion, contributing $19 \%$ of the total farm value of 60.5 billion (2017-8) (MLA 2018).

In Australia, the notion of spatially diversifying grazing properties to reduce the risk of drought can be traced back to 1890, when Sir Sydney Kidman established a chain of properties with the aim of becoming "drought proof." Properties were spread over large areas in an attempt to spread drought risk. Nonetheless, Kidman was never able to achieve his goal of having a drought-proof cattle company (Bowen 1987). Currently, several large grazing companies have strategically diversified their properties throughout Australia, e.g., the Northern Australian Pastoral Company (NAPCO) and the Australian Agricultural Company (AACo). Within these companies, and others, there is a network of properties (there are over 72 properties greater than $4000 \mathrm{~km}^{2}$ ) distributed across the grazing lands of Australia. However, while many grazing companies have spatially diversified their properties to spread risk, they do not actively incorporate dynamic climate information, such as ENSO, into their planning to inform the movement of cattle between properties.

Given the extensive areas, frequent and long drought periods, and higher annual variability in the growth of pastures occur in rangelands (Cobon et al. 2019), spatial diversification coupled with seasonal climate information could be of great benefit in making strategic and tactical adjustments to stock numbers. Namely, spatial diversification informed by climate information could provide guidance on how best to spread production under different climate conditions could help graziers reduce downside losses and maximize profits. While Australian's grazing industry is the focus of this paper, the proposed approach could be applicable to other industries worldwide where the businesses operate in various locations and climate impacts are dynamic and inhomogeneous, e.g., Anderson et al. (2019).

\section{Materials and methods}

\subsection{Data}

The four regions selected in this study are spread across northern Australia and include the Kimberley $\left(17.35^{\circ} \mathrm{S}, 125.92^{\circ} \mathrm{E}\right)$ in Western Australia (WTK), Barkly Tablelands $\left(19.00^{\circ} \mathrm{S}\right.$, $138.00^{\circ} \mathrm{E}$ ) in the Northern Territory (NBT) and the Central North $\left(19.38^{\circ} \mathrm{S}, 143.85^{\circ} \mathrm{E}\right)(\mathrm{QCN})$ and Charleville-
Longreach region $\left(24.33^{\circ} \mathrm{S}, 145.58^{\circ} \mathrm{E}\right)(\mathrm{QCL})$ in Queensland. These regions are important grazing areas and cover a range of climatic conditions, and so each is expected to expose graziers to different risks at different times (Fig. 1).

The pastoral industry, with an average of 13 million cattle, is the largest agricultural industry in northern Australia. The industry covers the whole of the Northern Territory and parts of Western Australia and Queensland above the Tropic of Capricorn (Mathew et al. 2018). Northern Australia accounts for approximately $55 \%$ of the national herd. In 2017, the total cattle number in the Northern Territory and Western Australia was just over 4.3 million, while Queensland's cattle herd was around 11 million. Queensland accounts for about half of the national cattle herd and is the largest beef producing state (MLA 2018). The grazing area in Queensland occupies $80 \%$ of the State and contributes over $30 \%$ of the total value of agricultural products in terms of meat, live animals, and wool (Johnston et al. 2000).

Aggregated farm business profit (\$) and total farm area operated (ha) datasets were collected from Meat and Livestock Australia (MLA), Department of Agriculture and Water Resources, Australian Government (http://apps. agriculture.gov.au/mla/mla.asp) from 1991 to 92 to 2017-18. The data are estimated according to the Australian financial year dates, which are 1 July to 30 June. The farm business profit of a farm is defined as the farm cash income plus building up in trading stocks, less depreciation, less the imputed value of the labor provided by the operator or manager, partners, and family. The aggregated farm business profit of each financial year is estimated based on the number of sampled farms in that year in the selected region with units in 2018-19 AUD. Similarly, the total farm area of each financial year is the operated area estimated from the number of sampled farms in the selected regions on 30th June each year. Table 1 shows the average number of farms, number of sample farms, area operated on 30 June, and average farm business profit over the period of 1991-2018.

Monthly values of Southern Oscillation Index (SOI), an ENSO indicator, were downloaded from the Australian Bureau of Meteorology (www.bom.gov.au). Monthly SOI data was used to classify ENSO events. El Niño (La Niña) years are defined if the 6-month average value of the SOI between June and March, starting in June and ending in any month between November and March, is below (above) a threshold value of negative (positive) 6.0. This means that if the 6-month average value of the SOI for any of the periods between June and November, July and December, August and January, September and February, or October and March is below (above) the threshold value of negative (positive) 6.0, that year will be classified as an El Niño (a La Niña) year. Neutral years are those which were not classified as either El Niño or La Niña. The threshold of \pm 6 was selected following the ENSO classifications of Stone et al. (2019). 
Table 1 Summary statistics of data (1991-2018) at four regions: The Kimberley in Western Australia (WTK), Barkly Tablelands in Northern Territory (NBT), Central North (QCN), and Charleville-Longreach (QCL) in Queensland, including averaged population, sample, area operated at 30 June, farm business profit, and standardized farm business profit with mean, maximum, minimum, and standard deviation (SD). Kendall's tau correlation coefficients between SOI and each standardized farm business profit and the corresponding $p$ values

\begin{tabular}{|c|c|c|c|c|}
\hline & WTK & NBT & QCN & QCL \\
\hline Averaged population (farms) & 57 & 27 & 631 & 611 \\
\hline Averaged sample (farms) & 9 & 11 & 35 & 31 \\
\hline Averaged area operated at 30 June $\left(000^{\prime}\right.$ ha $)$ & $304.0(22.63)$ & $673.2(11.22)$ & $42.6(30.41)$ & $20.9(16.11)$ \\
\hline Averaged farm business profit per year $\left(000^{\prime}\right)$ & $\$ 438.6(170.15)$ & $\$ 1846.6(87.74)$ & $\$ 49.7$ (214.96) & $\$ 36.8(77.56)$ \\
\hline \multicolumn{5}{|l|}{ Standardized farm business profit $(\$ / \mathrm{ha})$} \\
\hline Mean & 1.34 & 2.67 & 1.40 & 2.08 \\
\hline Maximum & 7.49 & 7.80 & 8.30 & 8.14 \\
\hline Minimum & -1.34 & -1.15 & -5.16 & -7.87 \\
\hline $\mathrm{SD}$ & 1.87 & 2.02 & 3.24 & 4.45 \\
\hline Kendall's tau vs. SOI & 0.12 & -0.06 & 0.23 & 0.29 \\
\hline$p$ value & 0.39 & 0.68 & 0.1 & 0.04 \\
\hline
\end{tabular}

The figures in brackets () are relative standard errors. Financial figures are converted to 2018-19 dollars

Population estimated number of farms in the selected categories, Sample number of sampled farms in the selected categories, Area operated at 30 June total farm area operated at 30 June, Farm business profit farm business profit-farm cash income plus build-up in trading stocks, less depreciation, less the imputed value of the labor provided by the operator or manager, partners, and family

\subsection{Optimizing portfolio using spatial diversification}

Suppose a producer operates his grazing system as a portfolio consisting of $n$ locations. Since across locations, the farm business profit and farm area are different from each other (Table 1), we standardized the data by dividing the farm business profit (\$) by the farm area (ha) to obtain the farm business profit $p_{i}(\$ / h a)$ of the location $i, i=[1, n]$. Henceforth, we use this terminology, i.e., farm business profit ( $\$ / \mathrm{ha})$, and use this data for all analyses.

It is assumed that, known and unknown climate information, the producer wants to make an optimal decision on how many percentages of the total production should be allocated to each region to achieve a pre-defined expected profit (i.e., the average of all profits) while managing the extent of potential loss in the expected profit over a given period of time for a specific confidence level (i.e., downside risk). This downside risk can be measured by CVaR. CVaR is superior to variance since it does not assume asset returns to be normally distributed. Further, it is a coherent and convex risk measure (Rockafellar and Uryasev 2000).

Let $w_{i}$ be the shared percent of the total production allocated to the region $i$ (i.e., the decision vector or weight). The portfolio optimization problem is to maximize the expected profit margin given a target risk (CVaR) level $\phi$ and confidence level $a$, which can be formulated as (Larsen et al. 2015):

$\operatorname{maximize} \sum_{i=1}^{n} w_{i} p_{i}$ subject to $\left\{\begin{array}{l}C V a R_{\alpha}\left(w_{i}\right) \leq \phi \\ \sum_{i=1}^{n} w_{i}=1\end{array}\right.$.

Rockafellar and Uryasev (2000) proposed an approximated sampling method to solve the CVaR function. Finally, the portfolio optimization problem can be reformulated as a linear programming problem. Readers are referred to Rockafellar and Uryasev (2000) for more details.

\subsection{Analysis methods-Vine copula model}

A statistical copula method was used to model the dependence structure between farm business profit and ENSO and generate data for the computation of the optimal portfolio model. Copula approaches make no assumption about distributions of variables (marginal) and the relationship between variables and so are suitable for modeling the joint distribution of multiple random variables. Recent years have witnessed a broad application of copula approaches in many fields such as finance and insurance (Fang and Madsen 2013), hydrology and water resources (Chowdhary et al. 2011), and systemic risk (Nguyen-Huy et al. 2019). The copula method has been also used in the studies of spatial diversification (Larsen et al. 2013; Larsen et al. 2015; Nguyen-Huy et al. 2018).

The computation of CVaR requires knowledge of the cumulative distribution function of all farm business profits of $n$ regions involved in the portfolio. Sklar (1959)'s theorem suggests that the joint distribution function $F($.) of $n$-dimensional random variables can be expressed as: 
$F\left(x_{1}, \ldots, x_{n}\right)=C\left[F_{1}\left(x_{1}\right), \ldots, F_{n}\left(x_{n}\right)\right]$,

where $C:[0,1]^{n} \rightarrow[0,1]$ is a copula function and $F_{i}\left(x_{i}\right)$ are marginal distributions of variables of interest, which is the profit of each farm in this case. It is clear that the dependence between variables is measured separately to the estimate of marginal distributions. Therefore, it does not restrict the distributions of each farm business profits and their distribution to have an elliptical distribution.

The marginal distributions (i.e., the distributions of each farm business profit and SOI) can be modeled using either parametric or non-parametric methods. Since the parametric copula functions are used in the later step, we estimate the marginal distributions non-parametrically using a kernel smoothing method to reduce the misspecification in the final model. The results of marginal fitting are then checked with histograms and quantile-quantile plots. This paper utilizes the vine copula to model the joint distribution of farm business profits and SOI since it enables us to build flexible dependence models for an arbitrary number of variables using Markov trees and bivariate building blocks (Bedford and Cooke 2002).

The most appropriate vine copula model was selected based on the Akaike Information Criterion (AIC). The copula parameters are estimated through maximum likelihood estimation method. A random vector is generated using the Monte Carlo method with the chosen copula model. In particular, SOI values are first randomly generated within [$17,-6]$ corresponding to El Niño, $[-6,6]$ for Neutral, and $[6,17]$ for La Niña events. The simulations of farm business profits conditioned on the three phases of SOI are repeated in 1000 times. The random data are then inversely transformed to obtain the simulated realizations of profit for each location using the quantile functions of the marginal distributions. Finally, the above optimization problem is solved using simulated realizations to derive the mean-CVaR efficient frontier. Analyses were performed using the R-packages: ks (Version 1.11.4) (Duong et al. 2019), VineCopula (Version 2.2.0) (Schepsmeier et al. 2018), and fPortfolio (Version 3042.83) (Wuertz et al. 2017).

\section{Results and discussion}

\subsection{The influence of ENSO on grazing profit varies across regions}

Out of the four regions, the correlation coefficient between SOI and QCL's profit is highest (significant at the 95\% level), followed by QCN (significant at the 90\% level) (Table 1). The statistical test shows that the impact of ENSO on annual farm business profit is insignificant in WTK and the correlation coefficient is almost zero in NBT. This indicates that ENSO has a different influence on beef industry profits across the four regions. Figure 2 also shows that ENSO has a stronger impact on farm business profits in Queensland regions (QCN and QCL). In Queensland, El Niño years (e.g., 2002-03, 2014-15) are often associated with losses, while La Niña years (e.g. 2000-01, 2010-12) are linked with aboveaverage profits (Fig. 2a). Figure $2 b$ shows that the median values of the farm business profits in Queensland regions to be high (gain) in La Niña events and low (loss) in El Niño and Neutral events. By contrast, the median values of the farm business profit are higher in WTK and NBT than in QLD regions in El Niño and Neutral events. Further, extended droughts (1991-95) cause sequential losses of profits in WTK and Queensland regions; however, this does not affect NBT (Fig. 2a). During consecutive La Niña events (19982001), QCL had the highest profit of all regions, though other regions still had positive profit. Maximum and minimum profits were often associated with different ENSO phases. For example, QCL achieved the highest profit in 2010-11, a La Niña year, while the lowest profits occurred in 2002-03, an El Niño year (Fig. 2a).

The chief driver of changes in profitability in each of these phases can be linked with changes in rainfall, which we map using the Standardized Precipitation Index (SPI) (Fig. 1) (Guttman 1999). Figure 1 indicates a strong relationship between the 6-month average SOI (used to classified ENSO years) and SPI (October-March, approximating the northern Australian wet season) in the QCN and QCL regions. However, the correlation coefficients are not significant in half of the NBT region, which may explain the weak relationship between SOI and farm business profits here (Table 1). The northern part of the WTK region exhibits a strong SOI-SPI relationship, but a weak SOI-profit relationship. This is likely because in the WTK most grazing occurs in the western and southern parts of the region, where the SOI-SPI correlation is lower. Differences in the strength of correlation between ENSO and rainfall explain in part the variation in the correlation between ENSO and grazing and profitability that we see between each region. These results are also consistent with previous research demonstrating the link between different ENSO phases and precipitation, in Australia and globally (Stone et al. 1996; Risbey et al. 2009; Cobon and Toombs 2013).

Variations in grassland communities between these regions could also influence the strength of the correlation between ENSO and profitability. Although we believe these differences are less important than variations in precipitation because of the grassland communities across all of the regions, our investigations are well adapted to arid conditions (e.g., acacia shrub shortgrass and xerophytic hummock grasslands) (Moore 1970). It should also be noted that the time series of farm business profit (Fig. 2) has a 
Farm Business Profit ( $\$ / h a)$

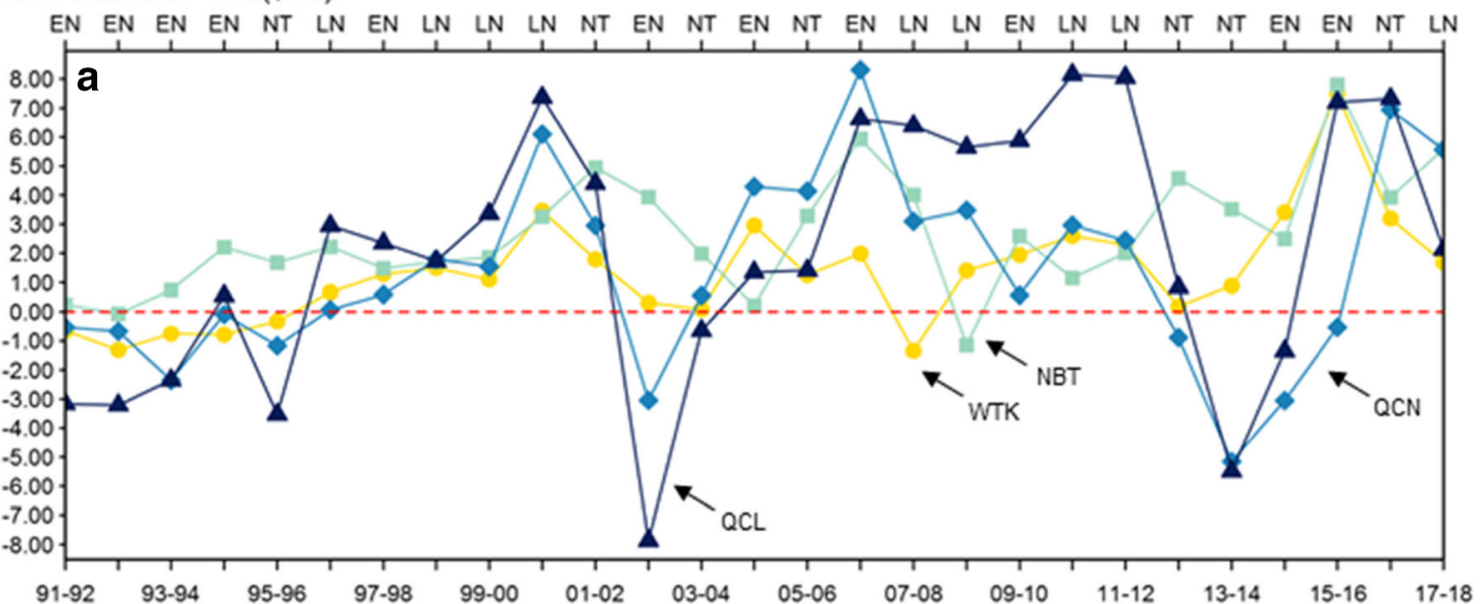

Farm Business Profit (\$/ha)

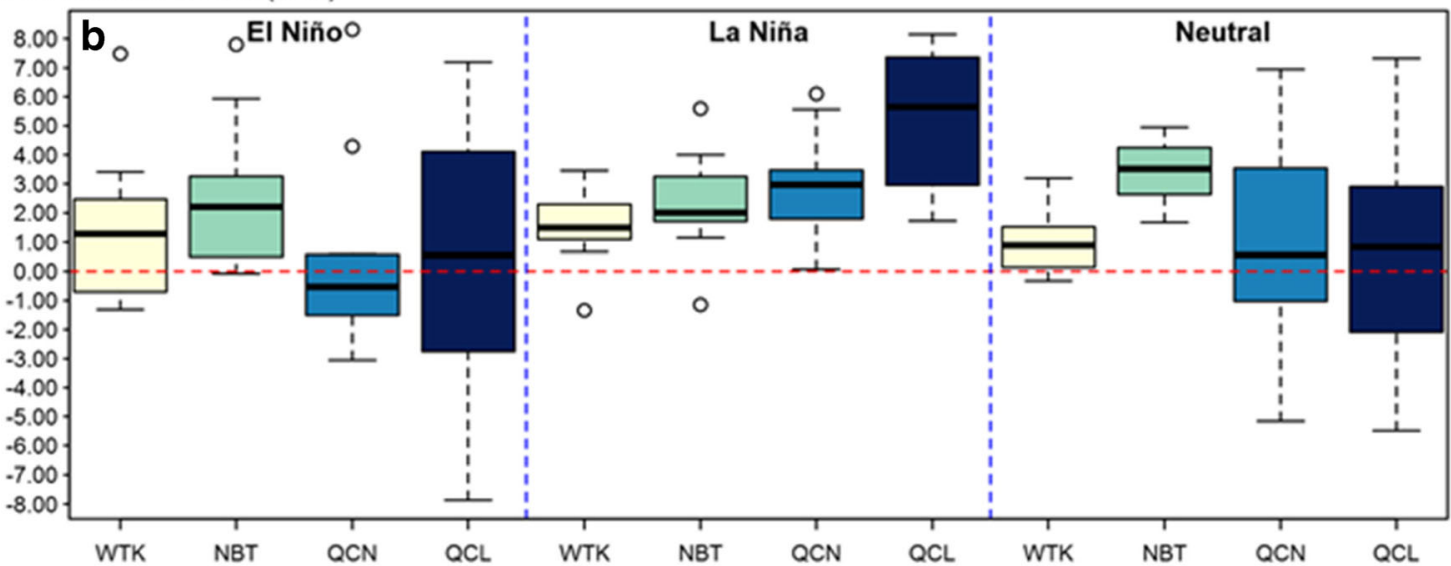

Fig. 2 a Historical annual farm business profit (1991-2018) of four regions: The Kimberley in Western Australia (WTK), Barkly Tablelands in Northern Territory (NBT), Central North (QCN), and Charleville-Longreach (QCL) in Queensland involving classified ENSO phases: El Niño (EN), La Niña (LN), and Neutral (NT). b Classified historical annual farm business profits according to different ENSO phases slightly positive trend in two regions (WTK and NBT). This is likely from, amongst other things, a combination of technical advances, genetic improvements in cattle, and more effective control of pests.

The QCL region has the widest range of annual business profits and losses, ranging from losses of about 7.87 to profits of about $8.14 \$ /$ ha corresponding with the largest standard deviation (Table 1). By contrast, the annual profits of WTK and NBT are more stable with standard deviations of 1.87 and $2.02 \$$ /ha, respectively. This could be because the influence of ENSO is weaker in the grazing areas of the WTK and NBT. Further, the probability of having annual profit below zero is relatively small in NBT, occurring in only two of the 27 years examined. However, while WTK and NBT profits are more stable than in QCN and QCL regions, maximum profits are substantially lower, potentially indicating that they are unable to capitalize on the favorable climate conditions associated with La Niña (Fig. 2b).
The spatiotemporally different influences of ENSO on annual beef business profit across these four regions suggest allocating beef business based on ENSO information could potentially optimize profits and reduce risk. Risbey et al. (2009) showed that the correlation between SOI and rainfall in the QCL region is significant in all seasons. However, the correlations between SOI and rainfall in NBT and QCN are not significant for the winter season (June-August). In particular, there is no correlation between SOI and rainfall in WTK for both autumn (March-May) and winter seasons. This relationship may explain the impact of ENSO and annual beef business profit, which is strong in the QCL, relatively equal in the NBT and QCN, and almost zero in the WTK. These results are consistent with research from Yuan and Yamagata (2015), who reported that La Niña events often bring more precipitation in eastern Australia; meanwhile, El Niño often results in drought. 


\subsection{Risk-return tradeoff options for a portfolio through a climate-based spatial diversification strategy}

This section outlines options for livestock producers to balance expected profit and risk using an ENSO informed spatial diversification strategy. The optimal portfolio models provide information on the percentage of production that should be allocated to each region with the corresponding expected business profit and risk. Figure 3 describes the ratio of the tradeoff between expected business profit and risk along the minimum variance locus (from the lowest risk (dashed line) to the left) and efficient frontier (from the lowest risk (dashed line) to the right). Higher expected business profits, at an equivalent level of risk, can be achieved along the efficient frontier (right-hand side of the dashed line in Fig. 3) compared to the minimum variance locus (left-hand side of the dashed line Fig. 3). Thus, a rational producer will hold a portfolio only on the efficient frontier (right-hand side of dashed line Fig. 3).

To reach the highest expected business profit, the results suggest allocating all production to NBT in El Niño or Neutral years (Fig. 3a-d), and to QCL in La Niña years. The optimized portfolio model offers options for graziers to reduce the risk by adjusting the percentage of production under different ENSO conditions. In particular, the model suggests one could shift production from the NBT to the WTK with specific ratios to satisfy both targets of expected business profit and risk when ENSO information is not used, or it is in El Niño or Neutral years. A similar strategy for risk reduction in La Niña years is feasible by shifting appropriate ratios of production from QCL to NBT and WTK. These findings are consistent with the analysis presented in Section 3.1 where the influence of ENSO on NBT and WTK is not significant and thus results in a small standard deviation (Table 1), and the median values of the expected business profits are always positive in all ENSO phases (Fig. 2b).

For example, a risk-taker portfolio manager may allocate production to QCL in a La Niña year to reach the highest expected business profit of $4.13 \$$ ha with the potential highest risk (or CVaR) of $8.54 \$ / \mathrm{ha}$, which is the average of all extreme losses lower or equal to the fifth percentile of the joint distribution of all business profits of the portfolio (Fig. 3c). However, in the same La Niña condition, a risk-averse farmer could instead shift about 23 and $20 \%$ of their production to WTK and NBT, respectively, for a risk reduction of $25 \%$ (from 4.13 to $3.08 \$ /$ ha) and a reduction in expected business profits of $41 \%$ (from 8.54 to $5.02 \$ /$ ha).

In general, the optimized portfolio models provide a wider range of risk reduction and profit increasing options relative to when ENSO information is used compared to when it is not. Risk (CVaR) is reduced by 15,86 and $22 \%$ from the highest level in El Niño, La Niña, and Neutral years, respectively, when using an ENSO-based optimization approach, compared to only a $5 \%$ risk reduction when no ENSO information is used. In all different phases, using ENSO-based optimization achieves the level of risks lower than in the model without ENSO information. The lowest values of risk in El Niño, La Niña, and Neutral years are, respectively, 1.23, 1.19, and $1.22 \$ /$ ha compared to $1.57 \$ /$ ha in the non-ENSO based optimization model. Further, in drought (i.e., El Niño), the difference in expected business profit obtained at the lowest level of risk between ENSO- and non-ENSO-based optimization is particularly notable. Using ENSO-based optimization, one can achieve an expected profit of $2.71 \$$ /ha in contrast to $2.30 \$ /$ ha from the model without ENSO information. Also at the lowest level of risk, the expected business profit derived from the ENSO-based optimization is 1.68 and 2.06 \$/ha during wet and average rainfall periods (i.e., La Niña and Neutral), respectively. Given the same values of expected profits, however, the non-ENSO-based optimization results in higher levels of risks, which are 1.81 (compared to $\mathrm{La}$ Niña) and $1.61 \$ /$ ha (compared to Neutral).

The differences between ENSO- and non-ENSO-based optimization is seen when equivalent percentages of production are allocated to the same regions. The optimized portfolio models integrated with ENSO information have a higher estimate of expected business profit and lower risk compared to those derived from the optimized model without ENSO. For example, allocating production as $80 \%$ NBT and $20 \%$ WTK, the non-ENSO-based model estimates the expected business profit and risk by 2.35 and $1.57 \$$ ha, respectively (Fig. 3a). However, when an El Niño year is identified, i.e., the model with ENSO information, the expected business profit and risk are 3.01 and $1.27 \$ /$ ha, respectively (Fig. 3b).

ENSO-based optimization also provides options to graziers to achieve much higher gains (expected profits of up to $\sim 4.13$ \$/ha), under La Niña, i.e., by allocating all production to QCL, the region where ENSO has the highest influence (Table 1; Fig. 3c). Shifting a part of the production to WTK and NBT can reduce the downside risk by reducing the expected business profit as well. However, the percentage of reduction for risk is higher than for expected profit. For example, with percentages of $68 \%$ in QCL, $16 \%$ in NBT, and $16 \%$ in WTK, the optimal portfolio model yields expected business profits of $3.34 \$ /$ ha and a CVaR of $5.89 \$ /$ ha (Fig. 3c). Relative to these allocation proportions, when all production is allocated to QCL, the profit is increased to $4.13 \$ /$ ha but the risk is also increased to $8.54 \$ /$ ha.

This is the first time that seasonal climate information has been coupled with a spatial diversification method to provide information to help graziers simultaneously reduce risk and increase profitability. These empirical findings highlight the effectiveness of a spatial diversification strategy to mitigate the impact of unfavorable ENSO conditions on agricultural production. In analyzing the risk-return tradeoffs, a portfolio manager must consider the business profit to diversification 

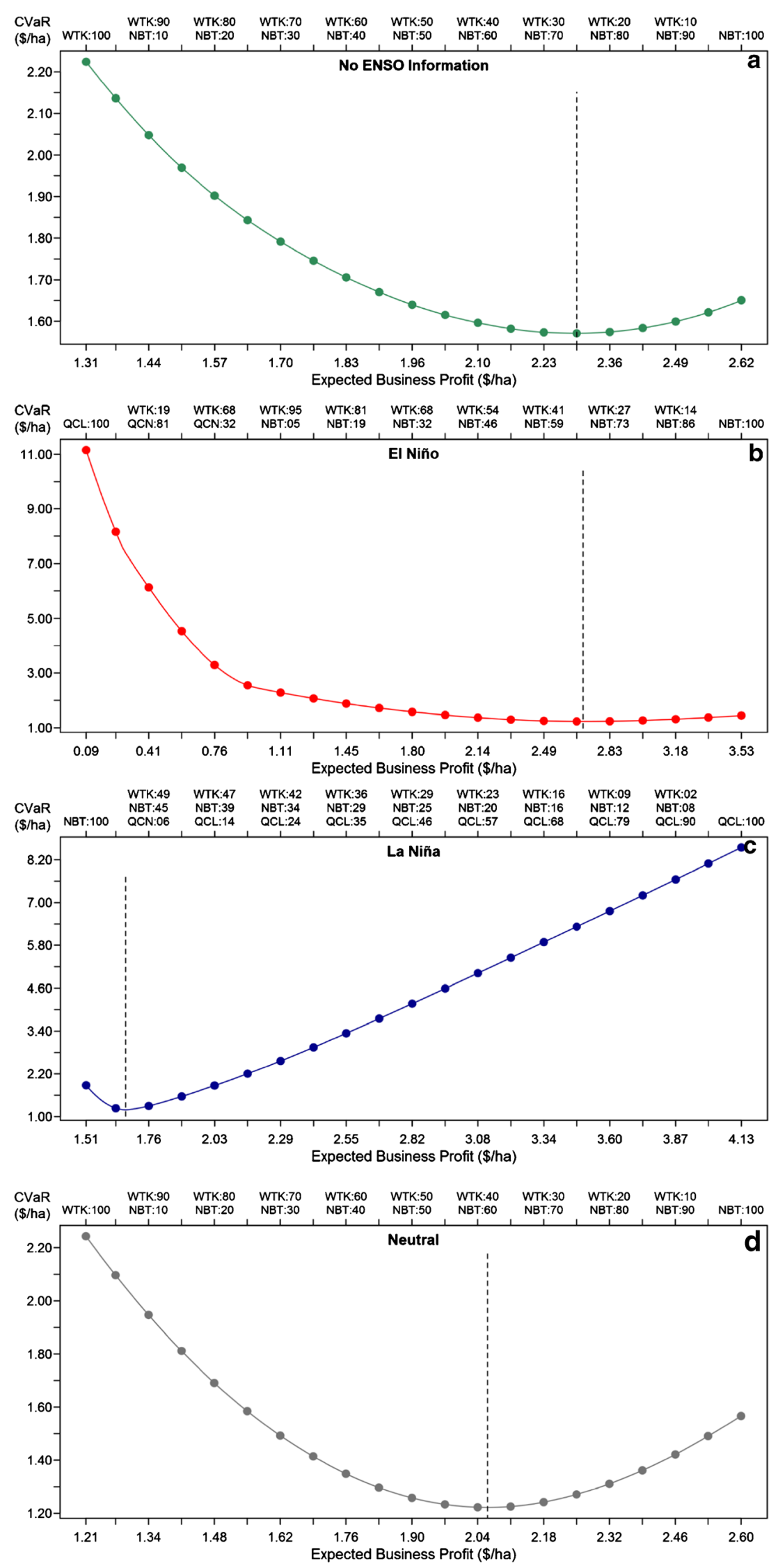
Fig. 3 Tradeoff analysis of optimized values between expected business profit and Conditional Value-at-Risk (CVaR) (a measure of financial risk, where higher values equate to more risk) in a spatial diversification in the cases of unknown ENSO information (a), El Niño (b), La Niña (c), and Neutral (d) phases with corresponding percentage of production allocated to each region: The Kimberley in Western Australia (WTK), Barkly Tablelands in Northern Territory (NBT), Central North (QCN), and Charleville-Longreach (QCL) in Queensland. For example, in the Neutral phase (d), WTK:20 and NBT:80 mean that allocating 20 and $80 \%$ of production to WTK and NBT, respectively, correspond with the optimized expected business profit of 2.32 (\$/ha) and risk (CVaR) of 1.31 (\$/ha). The dashed line indicates the position of the lowest risk. From this line to the left is the minimum variance locus. From this line to the right is the efficient frontier. CVaR measures the average of all extreme losses lower or equal to fifth percentile of the joint distribution of all business profits of the portfolio

options and the CVaR. Portfolio managers differ in the degree to which they take risk. Some managers are willing to take more risk than others (risk-takers) and some try to avoid taking risk (risk-averse). From the available evidence (Hurley 2010; Harwood et al. 1999), it appears that risk aversion is the most common attitude. The risk-averse managers are often more watchful decision-makers with preferences for less risky diversification options over maximizing business profit. Often, they are willing to accept lower business profit by choosing less risky portfolio diversification options (e.g., the dashed lines in Fig. 3).

Realizing the benefits of climate-based spatial diversification, of course, is predicated on production being moved relatively easily. Several large grazing companies do this in Australia already (e.g., NAPCO, AACO, CPC), but in a reactive manner (once pastures have reduced beyond a certain point). These companies own properties across multiple states, often separated by thousands of kilometers and regularly move cattle using large "road trains" between stations depending on feed availability. For example, the northern Australian Pastoral Company (NAPCO) owns multiple properties across the Northern Territory and Queensland and recently moved half a million cattle in a few months (Carmen et al. 2019). Moving livestock in response to ENSO information is therefore entirely feasible in the Australian context. In countries with well-developed transportation networks, the practical application of a climate-informed spatial diversification approach should also be feasible. In developing countries, herding and mustering, while more time consuming than transportation using trucks, could also be a viable option, but we acknowledge future research is needed to investigate this.

Additional to the financial benefits of climate-based spatial diversification outlined above, there are also several broader potential socioeconomic and environmental benefits. First, a climate-informed spatial diversification strategy could assist graziers to minimize the financial losses that often occur during drought. Second, there may be socioeconomic benefits for agricultural communities by spreading the benefits of agricultural production across multiple regions. Third, the approach offers a pro-active method for moving stock away from soon to be drought-impacted pastures, and as such should minimize land degradation from overgrazing. Overgrazing during droughts has caused widespread land degradation globally (Dregne 2002). Approaches that demonstrate the financial benefit to graziers of moving stock, for example before or during droughts, as we have here, could help reduce land degradation. Finally, we also computed the lag correlations between ENSO and farm business profits (cross-correlation) across the four locations. The correlation coefficients in 1- and 2-years ahead are higher than the concurrent relationship, implying a potentially prolonged impact of ENSO on farm business profits in the next and following years. The benefit of a climate-informed spatial diversification strategy could therefore economically benefit producers for multiple years.

\subsection{Limitations and future directions}

In this study, all analysis was carried out using ENSO information from the year that grazing profitability was collected. This was required to investigate the link between ENSO and grazing profitability and to test the utility of our approach. However, future research could adapt the method we outline and test the benefit of linking spatial diversification approaches with forecasts of ENSO. Thirty-year hind casts of ENSO for the 1981-2010 period yielded average correlation skills of 0.65 with a 6-month lead time (Barnston et al. 2012), suggesting it can be forecasted with some accuracy. Thus, the linking of ENSO forecasts with spatial diversification approaches could provide producers with greater lead times to adapt and spatially diversify their production systems, which could be particularly important for non-livestock producers that cannot move rapidly. This approach could be valuable in many areas aside from Australia, as ENSO strongly influences agricultural productivity in many parts of the world (e.g., eastern and southern Africa, Brazil, and large parts of southern and western South America, India, and northern China, Anderson et al. (2019)).

The benefit of ENSO-based spatial diversification approaches in practice would also need to carefully consider the costs of transportation (in the case of moving livestock) or switching production mode and crop (in the case of cropping). Having a number of properties spread across climatically different regions for graziers to move stock between is also another important practical limitation. Some smaller-scale graziers may not have the resources to purchase multiple properties. In Australia, larger grazing companies regularly move livestock large distances in response to pasture availability. However, for cropping enterprises, the costs of switching production practices could be far greater and 
also require much more lead time because production is typically more intense and expensive. As such for cropping systems, climate-based spatial diversification approaches may be less viable and/or perhaps only suitable when linked with sufficient ENSO forecasting lead time. Future research is therefore needed to test the utility of the approach we outline for non-livestock production.

Climate change projections show increases in the frequency and severity of extreme climate events and drier conditions in part of the world, particularly arid and semi-arid regions where most of the four study sites are (Godde et al. 2019). Alongside changing rainfall and temperature regimes that will make grazing more challenging, any alteration to ENSO under climate change, which while uncertain, are also likely to have widespread impacts (Vecchi and Wittenberg 2010). A method for spreading production risk that takes into account shifting or intensifying ENSO impacts could become increasingly important under climate change. The approach we outline is also adaptable to inform longer-term planning. For example, the risk spreading approach outlined could be used in combination with climate change projections to inform the optimal spread of production under different possible climate futures.

Finally, to better assess the utility of the climate-based spatial diversification approach we outline, higher resolution data, as well as information on other economic variables, such as cattle prices and the cost of transportation, is needed. We use aggregated spatial data on grazing profitability that covers large areas, but data at finer scales, within each region, may show different results - and thus different optimal solutions for minimizing risk and increasing profitability may be found. At these finer scales, data on cattle prices and the cost of transportation could also be important factors influencing climate-based spatial diversification. For example, if transport costs are high, or cattle prices low, then the economic benefits of diversification under different ENSO phases we show here could be either higher or lower and thus the optimal allocation of grazing lands could differ.

\section{Conclusion}

The benefit of spatial diversification has been shown for a range of agricultural production systems, but ours is the first study to demonstrate the benefit of coupling spatial diversification techniques with dynamic climate information. We demonstrated that by spatially diversifying production based on climate information, Australian graziers can simultaneously reduce risk and increase their profits. The optimal share of production allocated to each region varies depending on the target of the expected profit and risk for different climate conditions. The study also emphasizes the importance of involving ENSO information into the optimal portfolio model, particularly during El Niño and La
Niña. Climate-informed spatial diversification offers higher expected profits in drought (El Niño) relative to the non-climatebased model while minimizing risk (CVaR). Climate-informed spatial diversification also provides options to graziers to achieve much higher expected profits under La Niña in comparison to when no climate information is used. The approach we outline is applicable to other agricultural industries vulnerable to climate variability and in the future could be used to inform a priori seasonal climate risk management (e.g., strategic selling of stock and/or increasing production in certain areas in preference of others based on ENSO forecasts) to minimize (maximize) climate-related losses (profits) from unfavorable (favorable) climate conditions.

Acknowledgements The authors would like to acknowledge constructive comments from the reviewers and the Editor-in-Chief.

Funding information This study was funded by Meat and Livestock Australia Donor Company (MDC), the Queensland Government through the Drought and Climate Adaptation Program (DCAP), and the University of Southern Queensland. The projects involved are the "Northern Australia Climate Program" (NACP) and "Producing Enhanced Crop Insurance Systems and Associated Financial Decision Support Tools."

\section{Compliance with ethical standards}

Conflict of interest The authors declare that they have no conflict of interest.

\section{References}

Akponikpe PB, Minet J, Gérard B, Defourny P, Bielders CL (2011) Spatial fields' dispersion as a farmer strategy to reduce agroclimatic risk at the household level in pearl millet-based systems in the Sahel: a modeling perspective. Agric For Meteorol 151(2):215227. https://doi.org/10.1016/j.agrformet.2010.10.007

Allred BW, Scasta JD, Hovick TJ, Fuhlendorf SD, Hamilton RG (2014) Spatial heterogeneity stabilizes livestock productivity in a changing climate. Agric Ecosyst Environ 193:37-41. https://doi.org/10.1016/ j.agee.2014.04.020

Anderson W, Seager R, Baethgen W, Cane M, You L (2019) Synchronous crop failures and climate-forced production variability. Sci Adv 5(7):eaaw1976. https://doi.org/10.1126/sciadv.aaw1976

Barnston AG, Tippett MK, L'Heureux ML, Li S, DeWitt DG (2012) Skill of real-time seasonal ENSO model predictions during 2002-11: is our capability increasing? Bull Am Meteorol Soc 93(5):631-651. https://doi.org/10.1175/BAMS-D-11-00111.1

Bedford T, Cooke RM (2002) Vines: a new graphical model for dependent random variables. Ann Stat:1031-1068. https://doi.org/10. 1214/aos/1031689016

Bowen J (1987) KIdman: the forgotten king. The true story of the greatest pastoral landholder in modern history. Angus \& Robetson,

Bradshaw B, Dolan H, Smit B (2004) Farm-level adaptation to climatic variability and change: crop diversification in the Canadian prairies. Clim Chang 67(1):119-141. https://doi.org/10.1007/s10584-0040710-z

Bryan E, Deressa TT, Gbetibouo GA, Ringler C (2009) Adaptation to climate change in Ethiopia and South Africa: options and 
constraints. Environ Sci Pol 12(4):413-426. https://doi.org/10.1016/ j.envsci.2008.11.002

Carmen B, Matt B, Lydia B (2019) Calls for freight subsidies as 500,000 Barkly cattle trucked out in 'emergency' destocking. https://www. abc.net.au/news/rural/2019-06-07/transporters-battle-destockingemergency-on-barkly-stations/11184624.

Chowdhary H, Escobar LA, Singh VP (2011) Identification of suitable copulas for bivariate frequency analysis of flood peak and flood volume data. Hydrol Res 42(2-3):193-216. https://doi.org/10. 2166/nh.2011.065

Chowdhury R, Beecham S (2010) Australian rainfall trends and their relation to the southern oscillation index. Hydrol Process 24(4): 504-514. https://doi.org/10.1002/hyp.7504

Cobon D, Kouadio L, Mushtaq S, Jarvis C, Carter J, Stone G, Davis P (2019) Evaluating the shifts in rainfall and pasture growth variabilities across the Pastoral zone of Australia during the 1910-2010 period. Crop Pasture Sci 70(7):634-647. https://doi.org/10.1071/ CP18482

Cobon DH, Toombs NR (2013) Forecasting rainfall based on the Southern Oscillation Index phases at longer lead-times in Australia. Rangeland J 35(4):373-383. https://doi.org/10.1071/ RJ12105

Coppock DL (2011) Ranching and multiyear droughts in Utah: production impacts, risk perceptions, and changes in preparedness. Rangel Ecol Manag 64(6):607-618. https://doi.org/10.2111/REM-D-1000113.1

Duong T, Duong MT, Suggests M (2019) Package 'ks'

Eslake S (2018) Drought is a recurring feature of rural life in Australia, but its increased frequency may require a policy rethink. Company Director Magazine. Australian Institute of Company Directors https://doi.org/10.1016/j.insmatheco.2013.05.009

Fang Y, Madsen L (2013) Modified Gaussian pseudo-copula: applications in insurance and finance. Insurance: Insur Math Econ 53(1): 292-301. https://doi.org/10.1016/j.insmatheco.2013.05.009

Godde C, Dizyee K, Ash A, Thornton P, Sloat L, Roura E, Henderson B, Herrero M (2019) Climate change and variability impacts on grazing herds: insights from a system dynamics approach for semi-arid Australian rangelands. Glob Chang Biol. https://doi.org/10.1111/ gcb.14669

Guttman NB (1999) Accepting the standardized precipitation index: a calculation algorithm 1. J Am Water Resour Assoc 35(2):311-322. https://doi.org/10.1111/j.1752-1688.1999.tb03592.x

Harwood J, Heifner R, Coble K, Perry J, Somwaru A (1999) Market and trade economics division and resource economics division. USDAERS Agricultural Economic Report 774

Hurley TM (2010) A review of agricultural production risk in the developing world. https://doi.org/10.22004/ag.econ.188476

Johnston P, Mckeon G, Buxton R, Cobon D, Day K, Hall W, Scanlan J (2000) Managing climatic variability in Queensland's grazing lands - new approaches. In: Applications of seasonal climate forecasting in agricultural and natural ecosystems. Springer, pp 197226. doi:https://doi.org/10.1007/978-94-015-9351-9 14

Keogh M, Henry M, Clifton L (2015) The economic importance of Australia's livestock industries and the role of animal medicines and productivity-enhancing technologies. Australian Farm Institute, Sydney

Larsen R, Leatham D, Sukcharoen K (2015) Geographical diversification in wheat farming: a copula-based CVaR framework. Agr Finance Rev 75(3):368-384. https://doi.org/10.1108/AFR-07-2014-0020
Larsen RW, Mjelde J, Klinefelter D, Wolfley J (2013) The use of copulas in explaining crop yield dependence structures for use in geographic diversification. Agr Finance Rev 73(3):469-492. https://doi.org/10. 1108/AFR-02-2012-0005

Marty M, Lydia B, Ben S (2015) Before and after: how the drought is biting in regional Australia. ABC NEWS. https://www.abc.net.au/ news/2015-12-17/queensland-drought-photos-before-after/ 7035610 .

Mathew S, Zeng B, Zander KK, Singh RK (2018) Exploring agricultural development and climate adaptation in northern Australia under climatic risks. Rangeland J 40(4):353-364. https://doi.org/10.1071/ RJ18011

MLA (2018) Australia's beef industry. Fast Facts

Moore RM (1970) Australian grasslands. Australian grasslands

Nguyen-Huy T, Deo RC, Mushtaq S, Kath J, Khan S (2018) Copulabased agricultural conditional value-at-risk modelling for geographical diversifications in wheat farming portfolio management. Weather and Climate Extremes 21:76-89. https://doi.org/10.1016/ j.wace.2018.07.002

Nguyen-Huy T, Deo RC, Mushtaq S, Kath J, Khan S (2019) Copula statistical models for analyzing stochastic dependencies of systemic drought risk and potential adaptation strategies. Stoch Env Res Risk A 33:779-799. https://doi.org/10.1007/s00477-019-01662-6

Oba G (2001) The effect of multiple droughts on cattle in Obbu, Northern Kenya. J Arid Environ 49(2):375-386. https://doi.org/10.1006/jare. 2000.0785

Risbey JS, Pook MJ, McIntosh PC, Wheeler MC, Hendon HH (2009) On the remote drivers of rainfall variability in Australia. Mon Weather Rev 137(10):3233-3253. https://doi.org/10.1175/2009MWR2861.1

Rockafellar RT, Uryasev S (2000) Optimization of conditional value-atrisk. J Risk 2:21-42. https://doi.org/10.21314/JOR.2000.038

Schepsmeier U, Stoeber J, Brechmann EC, Graeler B, Nagler T, Erhardt T, Almeida C, Min A, Czado C, Hofmann M (2018) Package 'VineCopula'. R package version 2(5)

Sklar M (1959) Fonctions de répartition à $\mathrm{n}$ dimensions et leurs marges. Université Paris 8

Stone G, Dalla Pozza R, Carter J, McKeon G (2019) Long paddock: climate risk and grazing information for Australian rangelands and grazing communities. Rangeland J 41(3):225-232. https://doi.org/ 10.1071/RJ18036

Stone RC, Hammer GL, Marcussen T (1996) Prediction of global rainfall probabilities using phases of the Southern Oscillation Index. https:// doi.org/10.1038/384252a0

Trenberth KE (1997) The definition of el nino. Bull Am Meteorol Soc 78(12):2771-2778. https://doi.org/10.1175/1520-0477(1997) 078<2771:TDOENO >2.0.CO;2

Vecchi GA, Wittenberg AT (2010) El Niño and our future climate: where do we stand? Wiley Interdiscip Rev Clim Chang 1(2):260-270. https://doi.org/10.1002/wcc.33

Wuertz D, Setz T, Chalabi Y, Chen W, Setz MT, Rsocp S, Rnlminb R (2017) Package 'fPortfolio'

Yuan C, Yamagata T (2015) Impacts of IOD, ENSO and ENSO Modoki on the Australian winter wheat yields in recent decades. Scientific reports 5. doi:https://doi.org/10.1038/srep17252, 1, 8

Publisher's note Springer Nature remains neutral with regard to jurisdictional claims in published maps and institutional affiliations. 